\title{
T Cell Receptor Beta Chain Gene Rearrangement Shared by Murine T Cell Lines Derived from a Site of Autoimmune Inflammation
}

Steven J. Padula," Dennis C. Sgroi, ${ }^{\star}$ Elizabeth G. Lingenheld," James T. Love, Jr., Chi-Hsin J. Chou, ${ }^{\star}$ and Robert B. Clark *Division of Rheumatic Diseases, Department of Medicine, University of Connecticut School of Medicine, Farmington, Connecticut 06032; and $\ddagger^{\ddagger}$ Department of Neurology, Emory University School of Medicine, Atlanta, Georgia 30322

\begin{abstract}
Advances in our understanding of the structure and molecular biology of the $T$ lymphocyte antigen-receptor have now made it feasible to study human autoimmune diseases using new approaches. One such approach involves cloning of $T$ cells from sites of autoimmune pathology followed by identification of putative disease-related $T$ cell oligoclonality at the level of the $T$ cell receptor gene rearrangements. We have now tested the feasibility of this approach in an animal model of autoimmunity, murine experimental allergic encephalomyelitis (EAE). Spinal cord-derived, self (murine) myelin basic protein (MBP)-reactive $T$ cell lines and sublines were analyzed at the level of their receptor beta chain rearrangements using Southern blots. We now report that the MBP-reactive $T$ cell lines and sublines derived from the spinal cords of four of five SJL/J mice with EAE share a 14.5-kb rearranged $T$ cell receptor beta 1 band on Southern blots. A spinal cord-derived $T$ cell line that was reactive to purified protein derivative of tuberculin (PPD), several lymph node-derived ovalbumin- and PPD-reactive $T$ cell lines, as well as one MBP-reactive spinal cord-derived $T$ cell line did not share this $14.5-k b$ rearranged beta 1 band. These results suggest that analysis of the antigen receptors used by $T$ cells cloned from sites of inflammation may be a useful initial approach for identifying pathogenetically relevant $T$ cells in the study of certain human autoimmune diseases.
\end{abstract}

\section{Introduction}

Recent advances in the molecular biology of the T cell receptor are now allowing for novel approaches to the investigation of heretofore enigmatic diseases. One such group of diseases are those which are termed "autoimmune diseases." In certain of these autoimmune diseases such as RA and multiple sclerosis $(\mathrm{MS})^{1}, \mathrm{~T}$ cells appear to play an important part in the pathophysiology. Despite numerous studies of the peripheral blood

Address all correspondence to Dr. Steven J. Padula, Division of Rheumatic Diseases, University of Connecticut School of Medicine, Farmington, CT 06032.

Received for publication 21 May 1987 and in revised form 22 October 1987

1. Abbreviations used in this paper: EAE, experimental allergic encephalomyelitis; LN, lymph node; MBP, myelin basic protein; MS, multiple sclerosis; OVA, ovalbumin; PB, peripheral blood; PPD, purified protein derivative of tuberculin; SC, spinal cord.

J. Clin. Invest.

(c) The American Society for Clinical Investigation, Inc. 0021-9738/88/06/1810/09 \$2.00

Volume 81, June 1988, 1810-1818
T cells in patients with RA or MS, the etiology of these diseases remains unknown. Recent investigations have focused on $T$ cells derived from sites-of-pathology (i.e., the synovium in RA and the central nervous system in MS), and $T$ cell lines and clones have been derived from these sites-of-pathology $(1,2)$. However, despite the use of $\mathrm{T}$ cell cloning technology in these autoimmune diseases, relevant issues such as the antigen(s) of etiologic significance in such diseases remain unresolved. The lack of knowledge of disease-relevant antigens has, in turn, made the utilization of $\mathrm{T}$ cell cloning technology less than optimal. We have recently developed a strategy to deal with this problem using anti-T3 antibody in lieu of antigen $(3,4)$. With the development of DNA probes for the various gene segments of the $\mathrm{T}$ cell receptor a new approach for studying "autoimmune" diseases such as MS and RA has become feasible. The hypothesis underlying this approach is that if there are disease-specific antigens localized in the sites of pathology in these diseases, and if such antigens are eliciting $T$ cell-mediated inflammatory responses, then it may be possible to identify inflammatory site, disease-relevant populations of $\mathrm{T}$ cells even without knowledge of the "disease-specific antigens." Theoretically, such populations of inflammatory site, "disease-antigen-reactive" $T$ cells could be identified through characterization of the distinct clonal or oligoclonal patterns of rearranged genes encoding for their antigen receptors. Therapeutic efforts could then be focused on the elimination or inhibition of such possibly pathogenetic $\mathrm{T}$ cell clones.

Although great progress has been made in our understanding of the biochemical and genetic structure of the $T$ cell receptor, relatively little is known about the structure-function relationship between antigen, MHC determinants, and the T cell receptor (5-7). In addition, as yet, there has been no characterization of the antigen receptors used by $T$ cells responding in vivo to a known antigen at a site of inflammation.

Experimental allergic encephalomyelitis (EAE) is considered a prototypic animal model of a $\mathrm{T}$ cell-mediated autoimmune disease (8). In this model, sensitization of an animal with myelin basic protein (MBP) leads to a clinical and histological disease with many similarities to MS. We have recently shown that $\mathrm{T}$ cell lines can be derived directly from the central nervous system (the spinal cords) of mice with EAE (9). We have further demonstrated that, although such mice were sensitized to porcine MBP, the spinal cord (SC)-derived T cells were "autoreactive" in that they all also proliferated to murine (self) MBP (9). In contrast, we found that T cell lines derived from the peripheral blood (PB) of such mice were responsive to porcine MBP but were not (with one exception) responsive to murine (self) MBP (9). Thus, EAE, an autoimmune disease with a compartmentalized site-of-pathology and a well defined "relevant antigen," represents an ideal animal model for testing site-of-pathology $\mathrm{T}$ cell cloning followed by receptor gene analysis as an approach to studying human autoimmune dis- 
eases. We now report the identification of a $T$ cell receptor beta 1 gene rearrangement used by the SC-derived T cell lines from four of five mice with EAE.

\section{Methods}

Induction of EAE. EAE was induced in male $\mathrm{SJL} / \mathrm{J}$ mice, aged 4-8 wk (obtained from the National Institutes of Health). The mice used for the derivation of the SC T cell lines received sublethal (450 rad) irradiation from a Cs 137 source 2 wk before sensitization with MBP. Sensitization to MBP was induced by hind foot pad injections totaling $0.1 \mathrm{ml}$ and containing $100-250 \mu \mathrm{g}$ (total per mouse) of porcine MBP (Calbiochem-Behring Corp., La Jolla, CA) emulsified in an equal volume of CFA, which was supplemented with $6 \mathrm{mg} / \mathrm{ml}$ of desiccated Mycobacterium tuberculosis H37RA (Difco Laboratories, Inc., Detroit, MI). This sensitization was followed at 24 and $72 \mathrm{~h}$ by an intravenous injection of $2.2 \times 10^{10}$ formalin-fixed, washed Bordetella pertussis organisms (Michigan Department of Health). Sensitized mice were killed at the height of their clinical signs, 13-16 d after the injection of MBP, by exsanguination via cardiac puncture under ether anesthesia.

Clinical severity of EAE was assessed according to the criteria used by Knobler et al. (10): 0, no disease; 1, tail atonia, slight limb weakness; 2, hind limb paralysis, incontinence of bladder; and 3, moribund state or death due to EAE. Histological EAE was assessed according to the criteria of Knobler et al. (10): 0, no lesions; 1, few lesions, mainly leptomenigeal and ependymal; 2, numerous infiltrates in the white matter of the brain stem and cerebellum; 3 , florid lesions throughout the brain white matter.

Cell culture. T cell lines were derived from the SCs of mice with EAE as previously described (9). Briefly, after the mice were killed, their vertebral columns and a small amount of perivertebral tissue were removed under sterile conditions. Each SC was then removed from the vertebral column by injecting $5-10 \mathrm{ml}$ of air into the vertebral canal with an 18-gauge needle and a 10 -ml syringe. Each SC was put into a single cell suspension through a nylon mesh screen. The SC suspension was cultured in three to six wells of a 24-well multiwell plate (Costar Corp., Cambridge, MA). These cultures were established in complete media: RPMI 1640 (Biofluids, Inc., Bethesda, MD) with $100 \mathrm{U} / \mathrm{ml}$ penicillin, $100 \mu \mathrm{g} / \mathrm{ml}$ streptomycin, $10 \mu \mathrm{g} / \mathrm{ml}$ gentamycin, $10 \% \mathrm{FCS}$, and $5 \times 10^{-5} \mathrm{M} 2$-mercaptoethanol. Added to these cultures at their initiation were $10 \mu \mathrm{g} / \mathrm{ml}$ porcine MBP (a generous gift of Eli Lilly Co., Indianapolis, IN), 10-15\% IL-2, and 1-4 × $10^{6}$ irradiated $(1,300 \mathrm{rad}) \mathrm{SJL} / \mathrm{J}$ splenocytes per well. Our source of IL-2 was purified rat IL-2 (Collaborative Research, Inc., Lexington, MA) and crude supernatants of Con A-stimulated rat splenocytes to which alpha-methylmannopyranoside had been added to inhibit Con A activity. These cultures were fed twice per week with 10-15\% IL-2. Fresh irradiated $\mathrm{SJL} / \mathrm{J}$ splenocytes and porcine MBP were added biweekly. As T cells became morphologically apparent in the cultures, the cultures were expanded into additional wells as needed. For SC-derived T cell lines that were reactive to the purified protein derivative of tuberculin (PPD), similar protocols were used except that PPD was used instead of porcine MBP in the in vitro propagation of the lines. PB-derived lines were generated as above, with the only difference being the use of $10-50 \mu l$ of heparinized whole blood rather than SC tissue to initiate the cultures. As above, such cultures were also initiated and fed by using porcine MBP, irradiated SJL/J splenocytes, and 10-15\% IL-2. The small amount of blood used to initiate such lines was obtained via cardiac puncture in heparinized syringes at the time the mice were killed.

Lymph node ( $\mathrm{LN}$ )-derived $\mathrm{T}$ cell lines were generated from a single cell suspension of popliteal LNs taken from a nonirradiated SJL/J mouse $10 \mathrm{~d}$ after sensitization to porcine MBP with CFA and $B$. pertussis as described above. In addition to porcine MBP, we also used ovalbumin (OVA) and CFA alone (to generate PPD-reactive cells) as sensitizing antigens. Such $L N$ cells were cultured for $3 d$ with antigen in the absence of exogenous IL-2 or irradiated splenocytes. After $3 \mathrm{~d}$, such cultures were fed with irradiated splenocytes, antigen, and exogenous IL-2, and maintained as described for the SC-derived lines, except that recombinant human IL-2 (Amgen Biologicals, Inc., Thousand Oaks, $\mathrm{CA}, 2 \mathrm{U} / \mathrm{ml}$ ) was used.

Subculturing and cloning of SC-derived $T$ cell lines. SC-derived T cell sublines were subcultured by plating such cells at 10 cells/well in round-bottom 96-well plates (Costar Corp.) along with IL-2, $2 \times 10^{5}$ irradiated SJL/J splenocytes, and porcine MBP. These cultures were then fed as described above. For cloning, the subcultured line SC-2.17 (derived from a 10-cell/well culture) was further cultured at 1 cell/well and one growing clone was selected and once again cultured at 0.3 cells/well. Clone SC-2.17.17.11 was thus derived from three successive limiting dilution cultures at 10,1 , and 0.3 cells/well.

Subculturing and cloning of $L N$-derived $T$ cell lines. $L N$-derived $T$ cell sublines OVA 1.28 and PPD 1.24 were obtained from the 3-d-old LN cultures by two successive limiting dilution cultures at 10 and 1 cell/well as described above. LN-derived T cell subline OVA 0.15 was obtained by culturing cells at 1 cell/well directly from the 3-d-old initial cultures. In all limiting dilution cultures, fewer than $50 \%$ of the seeded wells grew.

Proliferation assay. T cell lines or clones to be tested were plated at $2 \times 10^{4}$ cells/well in flat-bottom 96-well microtiter plates (Costar Corp.) in complete media in the absence of IL-2. To these T cells were added $3 \times 10^{5}$ irradiated (1,300 rad) $\mathrm{SJL} / \mathrm{J}$ splenocytes and either no antigen (media control) or various antigens at $10-25 \mu \mathrm{g} / \mathrm{ml}$. PPD was obtained from Connaught Laboratories Ltd., Swiftwater, PA. Murine MBP was a generous gift of Dr. Elisa Barbarese, University of Connecticut Medical School, and was prepared as previously described (11). OVA was obtained from Sigma Chemical Co., St. Louis, MO. The porcine MBP was a generous gift of Eli Lilly Co. 1 or $2 \mu \mathrm{Ci}$ of $\left[{ }^{3} \mathrm{H}\right]-$ thymidine (New England Nuclear, Boston, MA) were added to each well at $48 \mathrm{~h}$ and the cultures were harvested with the aid of a semiautomated cell harvester $18 \mathrm{~h}$ later. The radioactivity incorporated into cellular DNA was then assayed using a beta scintillation counter. The mean and one SE of counts per minute of $\left[{ }^{3} \mathrm{H}\right]$ thymidine incorporated were calculated from duplicate or triplicate wells.

Generation of peptide fractions from guinea pig MBP. Guinea pig MBP was cleaved into three main fractions by limited digestion with pepsin, and the three fragments (amino acid residues 1-38, 45-88, and 89-167) were isolated by column chromatography on CM-52 as described in Chou et al. (12).

Isolation of DNA. DNA was prepared as previously described with minor modifications (13). T cells were washed two to three times in PBS, resuspended in TES ( $20 \mathrm{mM}$ Tris- $\mathrm{HCl}$ [pH 8.0], 1 mM EDTA, 10 $\mathrm{mM} \mathrm{NaCl}$ ), and added to an equal volume of TES containing proteinase $\mathrm{K}(200 \mu \mathrm{g} / \mathrm{ml})$ and $1 \%$ SDS. The suspension was incubated overnight at $50^{\circ} \mathrm{C}$. The DNA then was extracted once with phenol/chloroform/isoamyl alcohol and several times with chloroform/isoamyl alcohol, and then was precipitated with an addition of $\mathrm{NaCl}$ to a final concentration of $100 \mathrm{mM}$ and $2 \mathrm{vol}$ of ethanol. The precipitated DNA was then removed with a curved pipette tip and resuspended in TE (10 $\mathrm{mM}$ Tris- $\mathrm{HCl}$ [pH 7.5], $1 \mathrm{mM}$ EDTA). DNase-free RNase was then added to a final concentration of $100 \mu \mathrm{g} / \mathrm{ml}$ and the sample was incubated at $37^{\circ} \mathrm{C}$ for $1 \mathrm{~h}$. This was followed by the addition of proteinase $\mathrm{K}$ to a final concentration of $100 \mu \mathrm{g} / \mathrm{ml}$, and SDS to a final concentration of $0.5 \%$ for a $1-\mathrm{h}$ incubation at $50^{\circ} \mathrm{C}$. The DNA was again extracted, precipitated, and isolated as described above and resuspended in TE. The concentration of DNA was determined by spectroscopy. The $A_{260} / A_{280}$ ratio of all samples was 1.8-2.0.

Liver, used as a source of germ line DNA, was obtained from 6-8-wk-old SJL/J mice (obtained from the National Institutes of Health) and homogenized briefly with a Polytron (Brinkmann Instruments Co., Westbury, NY) in HBSS. The cell suspension was then treated in the same manner as above.

Southern blot analysis. DNA was cut with restriction enzymes Eco RI and Hind III according to the recommendations of the supplier (Bethesda Research Laboratories, Gaithersburg, MD). $15 \mu \mathrm{g}$ of di- 
gested DNA was separated on $0.8 \%$ agarose gels in Tris-acetate buffer and transferred to nitrocellulose paper according to the method of Southern (14). The filters were hybridized in $0.60 \mathrm{M} \mathrm{NaCl} / 0.060 \mathrm{M}$ sodium citrate ( $\mathrm{pH} 7.0$ ), $40 \%$ formamide, $10 \%$ dextran sulfate, $0.016 \%$ Ficoll, $0.016 \%$ BSA, $0.016 \%$ polyvinylpyrrolidone, $7 \mathrm{mM}$ Tris- $\mathrm{HCl}$ (pH 7.5), $100 \mu \mathrm{g} / \mathrm{ml}$ sonicated salmon sperm DNA, and $10^{6} \mathrm{cpm} / \mathrm{ml}$ radioactive probe. Hybridization was performed at $42^{\circ} \mathrm{C}$ for $12-16 \mathrm{~h}$. Filters were washed at room temperature in $0.30 \mathrm{M} \mathrm{NaCl} / 0.030 \mathrm{M}$ sodium citrate $(\mathrm{pH} 7.0), 0.1 \%$ SDS for $20 \mathrm{~min}$, which was repeated once, and then they were washed at high stringency in $0.03 \mathrm{M}$ $\mathrm{NaCl} / 0.003 \mathrm{M}$ sodium citrate ( $\mathrm{pH} 7.0$ ), $0.1 \% \mathrm{SDS}$ at $65^{\circ} \mathrm{C}$ for $15 \mathrm{~min}$ two times. Filters were then air dried and exposed for 16-24 h to Kodak XAR -5 film at $-70^{\circ} \mathrm{C}$ using intensifying screens.

Probes. The Jbeta 1 and Jbeta 2 region probes were isolated from two genomic clones kindly provided by Dr. Stephen Hedrick, University of California, San Diego, CA (5). The Jbeta 1 probe is a 1.3-kb fragment extending from the Sph I site $5^{\prime}$ to Jbeta 1.4 , to the Sac I site $3^{\prime}$ to Jbeta 1.7. The Jbeta 2 probe is a 1.2-kb Eco RI-Cla I fragment spanning the entire Jbeta 2 region. These Jbeta probes will detect all beta chain rearrangements when DNA is digested with Hind III or Eco $R 1(5,6)$. The probes were radiolabeled to a specific activity of $10^{9}$ $\mathrm{cpm} / \mu \mathrm{g}$ by using random oligonucleotide primers and the large fragment of DNA polymerase I with [alpha- $\left.{ }^{32} \mathrm{P}\right] \mathrm{dCTP}$ after the method of Feinberg and Vogelstein (15).

\section{Results}

Generation of $T$ cell lines and clones. As previously described, mice 2-6 were all suffering from grade 3 clinical EAE with bilateral fore- and hindlimb paralysis when killed (9). All mice were killed between days 13 and 16 after sensitization with CFA and MBP. Mouse 9 had no clinical signs of EAE after MBP sensitization, but had grade 2 changes of histological EAE. The SC cultures of mice 2-6 were propagated with IL-2, syngeneic irradiated splenocytes (as antigen presenting cells), and porcine MBP as previously described (9). The SC cultures of mouse 9 were propagated similarly, except that the PPD was used instead of porcine MBP.

The T cells that grew from the SC cultures of mice 2-6 were termed lines SC-2, SC-3, SC-4, etc. The T cell line generated from the SC of mouse 9 was termed SC-9-PPD. Thus, each $\mathrm{T}$ cell line represents a heterogeneous $\mathrm{T}$ cell population grown from the SC of an individual mouse. These lines had been propagated in culture (with intermittent periods of cryopreservation) in our laboratory over a period of $\sim 6$ mo when studied. In addition, SC- 2 and SC-4 were subcultured at 10 cells/well, and SC-5 was subcultured at 1 cell/well, and the resulting sublines (SC-2.10, SC-2.17, SC-4.1, SC-4.7, and SC-5.0.9.) had also been maintained for $\sim 6$ mo when studied. In addition, one of these sublines, SC-2.17, has been cultured at $1 \mathrm{cell} /$ well yielding the subline SC-2.17.17, and then cultured again at 0.3 cell/well yielding the clone SC-2.17.17.11. In all of the above subcultures, fewer than $35 \%$ of the seeded wells yielded growing lines, and in the final subcultures for SC-2.17.17.11 (at 0.3 cell/well) only $15 \%$ of the seeded wells yielded growing clones.

$10 \mu \mathrm{l}$ of heparinized blood, obtained via cardiac puncture at the time of the killing of mouse 5 (and propagated as with the SC-derived lines), gave rise to the line PB-5 as previously described (9). Line JHL was derived from the popliteal LNs of an $\mathrm{SJL} / \mathrm{J}$ mouse sensitized with $\mathrm{CFA}$, porcine $\mathrm{MBP}$, and $B$. pertussis. These $\mathrm{LN}$ cells were initially stimulated for $3 \mathrm{~d}$ with porcine MBP in the absence of exogenous IL-2, and thereafter propagated using the same protocol as for the SC-derived lines. Line JHL has been maintained in culture intermittently (with cryopreservation) over the past 3 mo. T cell lines OVA 0.15 , OVA 1.28, and PPD 1.24 were derived from the popliteal LNs of SJL/J mice sensitized with either OVA and CFA or with CFA alone.

Proliferative response of $T$ cell lines and clones. As seen in Table I, SC-2 through SC-6, their sublines, and clone SC-2.17.17.11 all respond to both porcine MBP (the immunogen) and to self (murine) MBP. We have previously demonstrated that PB-derived lines from these mice, although propagated in vitro in a fashion similar to the SC-derived lines, often respond to porcine $\mathrm{MBP}$, but do not usually respond to murine MBP (9). The only PB-derived line that initially showed any reactivity to self (murine) MBP was PB-5 (9), though this line has become nonresponsive to murine MBP over time in culture (Table I). As can be seen in Table I, SC-2 through SC-6

Table I. Proliferative Responses of T Cell Lines, Sublines, and Clones

\begin{tabular}{lcccc}
\hline & \multicolumn{3}{c}{ cpm TdR* } \\
\cline { 2 - 5 } Clone/line & Media & Porcine MBP* & Murine MBP* & PPD \\
\hline SC 2 & $114 \pm 18$ & $5,976 \pm 162$ & $1,349 \pm 152$ & $100 \pm 11$ \\
SC 2-10 & $645 \pm 223$ & $48,713 \pm 6,278$ & $34,434 \pm 3,049$ & $1,491 \pm 264$ \\
SC 2-17 & $1,064 \pm 313$ & $192,410 \pm 21,388$ & $12,921 \pm 3,441$ & NT \\
SC 2.17.17.11 & $2,314 \pm 215$ & $17,818 \pm 476$ & $15,797 \pm 1,055$ & $1,078 \pm 373$ \\
SC 3 & $134 \pm 26$ & $11,714 \pm 742$ & $3,332 \pm 197$ & $104 \pm 19$ \\
SC 4 & $186 \pm 41$ & $11,742 \pm 1,039$ & $16,194 \pm 669$ & $228 \pm 56$ \\
SC 4.1 & $570 \pm 155$ & $75,516 \pm 560$ & $11,839 \pm 206$ & $540 \pm 138$ \\
SC 4.7 & $732 \pm 240$ & $100,934 \pm 10,668$ & $77,300 \pm 1,818$ & $475 \pm 33$ \\
SC 5 & $138 \pm 11$ & $7,352 \pm 975$ & $3,484 \pm 477$ & $56 \pm 5$ \\
SC 5.0.9 & $316 \pm 36$ & $24,543 \pm 2,021$ & $18,028 \pm 2,803$ & NT \\
PB 5 & $1,216 \pm 32$ & $14,810 \pm 1,135$ & $2,151 \pm 161$ & $1,542 \pm 60$ \\
SC 6 & $658 \pm 129$ & $14,902 \pm 5,729$ & $4,821 \pm 525$ & $1,136 \pm 199$ \\
SC 9-PPD & $280 \pm 54$ & $476 \pm 45$ & $233 \pm 20$ & $1,532 \pm 2,970$ \\
JHL & $3,443 \pm 1,080$ & $18,641 \pm 1,817$ & $16,738 \pm 1,483$ & $1,980 \pm 469$
\end{tabular}

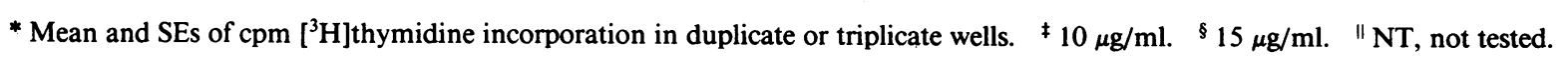


Table II. Proliferation of T Cell Lines, Sublines, and Clones to Fragments of MBP

\begin{tabular}{|c|c|c|c|c|c|}
\hline \multirow[b]{2}{*}{ Clone/line } & \multicolumn{5}{|c|}{ cpm TdR* } \\
\hline & Media & GPMBP & $\begin{array}{c}\text { GP-Fx } 1^{\ddagger} \\
\text { (amino acid 45-88) }\end{array}$ & $\begin{array}{c}\text { GP-Fx } 2 \\
\text { (amino acid 1-38) }\end{array}$ & $\begin{array}{c}\text { GP-Fx } 4 \\
\text { (amino acid 89-167) }\end{array}$ \\
\hline SC 2 & 254 & 44,705 & 320 & 323 & 274 \\
\hline SC 2.10 & 299 & 31,006 & 385 & 294 & 370 \\
\hline SC 2.17 & 403 & 194,987 & 450 & 554 & 405 \\
\hline SC 2.17.17.11 & 1,229 & 295,125 & 1,899 & 1,527 & 1,210 \\
\hline SC 3 & 411 & 26,448 & 450 & 420 & 404 \\
\hline SC 4 & 380 & 44,701 & 1,126 & 1,318 & 830 \\
\hline SC 4.1 & 260 & 36,514 & 381 & 573 & 367 \\
\hline SC 4.7 & 533 & 36,919 & 574 & 592 & 575 \\
\hline SC 5 & 1,539 & 16,814 & 964 & 4,890 & 2,718 \\
\hline SC 5.0.9 & 346 & 35,880 & 501 & 268 & 211 \\
\hline PB 5 & 1,216 & 15,592 & 2,197 & 1,786 & 1,497 \\
\hline SC 6 & 711 & 8,760 & 668 & 769 & 1,274 \\
\hline JHL & 3,436 & 47,352 & 210,851 & 160,400 & 68,037 \\
\hline
\end{tabular}

\footnotetext{
* Mean counts per minute $\left[{ }^{3} \mathrm{H}\right]$ thymidine incorporation in duplicate or triplicate wells. SEs were $<25 \%$ of the means in all cases. ${ }^{\ddagger} \mathrm{GPMBP}$ the intact guinea pig myelin basic protein molecule; GP-Fx, guinea pig myelin basic protein fragments; the intact molecule and the fragments are tested at $15-25 \mu \mathrm{g} / \mathrm{ml}$.
}

and their sublines do not respond to PPD. Line JHL also responds to both porcine MBP and to murine MBP, but not to PPD. In contrast and as expected, SC-9-PPD, propagated with PPD rather than MBP, responds to PPD but not to either porcine or murine MBP.

We have now assayed the proliferative responses of the SC-derived lines, sublines, and clones from mice 2-6, the PBderived line from mouse 5 , and line JHL to the pepsin-digested fragments of guinea pig MBP. As can be seen in Table II, while PB-5 and all of the SC-derived lines and sublines respond to (the intact) guinea pig MBP, all except SC-4 and SC-5 fail to respond to any of the three pepsin-digested fragments of the guinea pig MBP molecule. SC-4 and SC-5 (though not their sublines) demonstrate a very small response to fragment 2 , and SC-4 also demonstrates a very small response to fragment 1 . In general, however, PB-5 and the SC-derived lines and sublines from mice 2-6 all appear to respond primarily to a tertiary conformational determinant on the guinea pig MBP molecule or to an overlap determinant lost in producing the MBP fragments. A similar specificity for a tertiary conformational or overlap epitope of the MBP-molecule has been previously described among $\mathrm{LN}$-derived $\mathrm{T}$ cell clones derived from $\mathrm{SJL} / \mathrm{J}$ mice sensitized to MBP (16). Our LN-derived T cell line, JHL, though propagated in vitro in the same fashion as the SC-derived lines, demonstrates a different fragment response. Line JHL responds to the intact guinea pig MBP molecule and also to all three fragments of guinea pig MBP. Thus, despite the use of similar propagation protocols for the SC-derived lines, the PB-derived lines, and the LN-derived lines, the in vitro propagation (with IL-2, porcine MBP, and irradiated splenocytes) did not always select for populations with the same reactivity. The LN-derived lines, OVA 0.15 and OVA 1.28 , proliferate specifically to OVA, and the LN-derived line PPD 1.24 proliferates specifically to PPD (data not shown).

Southern blot analysis. We next sought to determine whether our SC-derived T cell lines and sublines, though derived from separate mice, use $\mathrm{T}$ cell receptor beta chain genes that give similar restriction fragment bands on Southern blot analysis. DNA was isolated from each of the SC-derived T cell lines and sublines, from the LN-derived line, JHL, from the PB line PB-5, and from SJL/J liver, and was digested to completion with restriction endonucleases, transferred to nitrocellulose filters, and hybridized to Jbeta probes. It should be

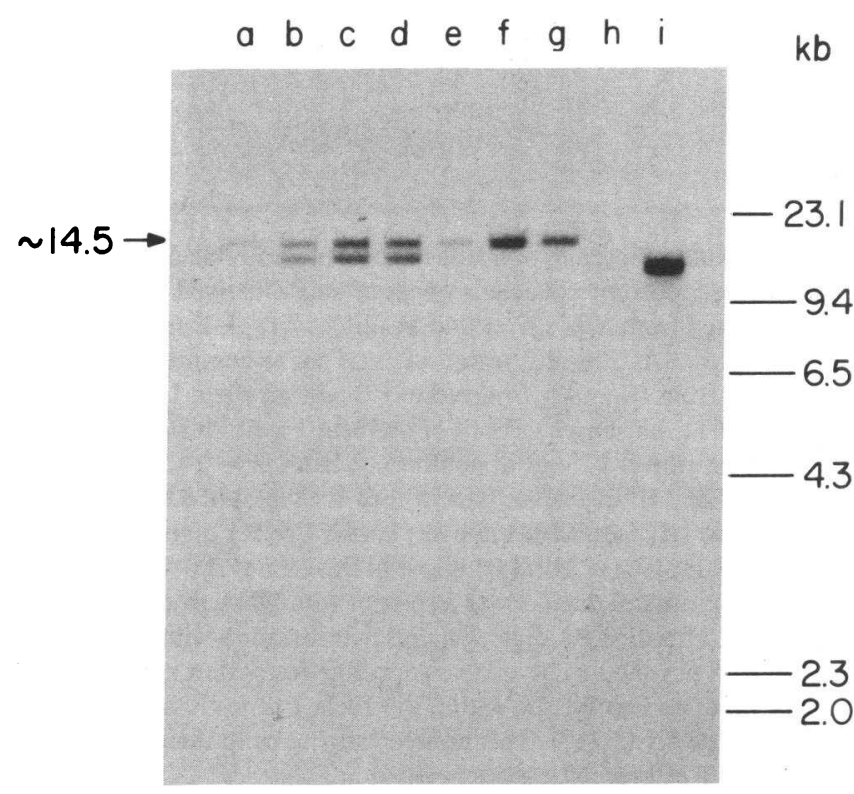

Figure 1. Autoradiograph of Southern blot of germ line and rearranged $\mathrm{T}$ cell receptor beta chain genes. DNA isolated from $\mathrm{SJL} / \mathrm{J}$ liver and SC-derived lines and sublines from SJL/J mice with EAE was cut to completion with Hind III and hybridized to ${ }^{32} \mathrm{P}$-labeled Jbeta 1 probe. A band at $\sim 14.5 \mathrm{~kb}$ was seen with all of the MBPreactive SC-derived T cell lines and sublines. SC-9-PPD is an SC-derived T cell line reactive to PPD. Lane $a, \mathrm{SC}-4$; lane $b$, SC-2; lane $c$, SC-2.10; lane $d$, SC-2.17; lane $e$, SC-3; lane $f$, SC-4.1; lane $g$, SC-4.7; lane $h$, SC-9-PPD; lane $i$, SJL/J liver. 


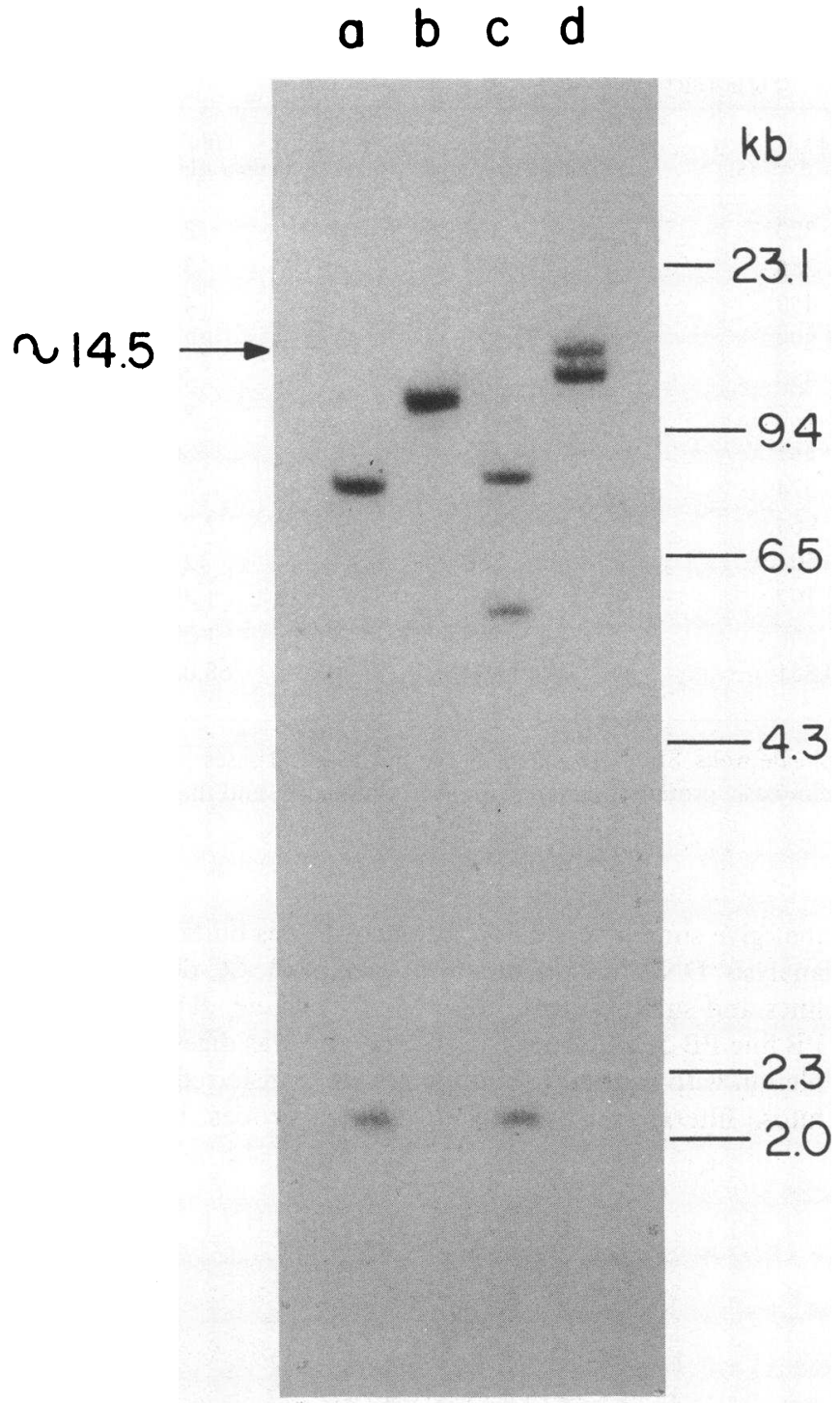

Figure 2. Autoradiograph of Southern blot of germ line and the rearranged $\mathrm{T}$ cell receptor beta chain genes of an SC-derived $\mathrm{T}$ cell clone. DNA isolated from SJL/J liver and SC-2.17.17.11, a T cell clone derived from an SJL/J mouse with EAE, was cut to completion with Eco R1 or Hind III and hybridized to ${ }^{32} \mathrm{P}$-labeled Jbeta 1 probe. SC-2.17.17.11 rearranges to both of its Jbeta 1 gene clusters as previously seen with SC-2 and its sublines. A band at $\sim 14.5 \mathrm{~kb}$ is again seen with Hind III digestion. Lane $a$, Eco R1 digest of SJL/J liver; lane $b$, Hind III digest of SJL/J liver; lane $c$, Eco RI digest of SC-2.17.17.11; lane $d$, Hind III digest of SC-2.17.17.11. The band at $2.1 \mathrm{~kb}$ seen in lanes $a$ and $c$ was also seen with DNA from all of the $T$ cell lines after Eco R1 digestion and hybridization with the Jbeta 1 probe (data not shown). Available germ line restriction maps do not demonstrate an Eco R1 site within the Jbeta 1 gene cluster to account for the $2.1 \mathrm{~kb}$ (17). This nonrearranging band therefore represents non- $T$ cell receptor sequences.

noted that these $\mathrm{J}$ probes detect all beta chain rearrangements when DNA is digested with Hind III or Eco R1 $(5,6)$. As shown in Figs 1-6 and discussed below, we found a pattern of restriction fragments consistent with an oligoclonal distribution of beta chain rearrangements among the MBP-reactive SC-lines from four of five mice. This was true despite the fact

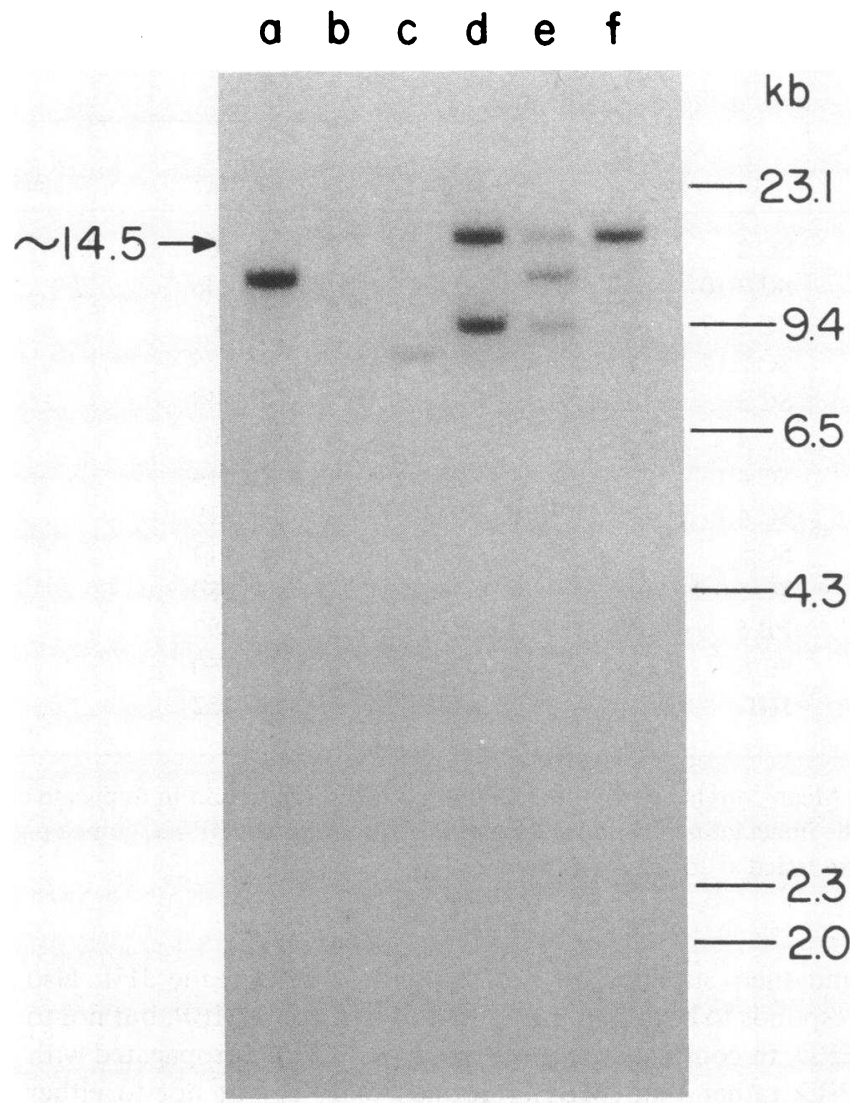

Figure 3. Autoradiograph of Southern blot of germ line and rearranged $T$ cell receptor beta chain genes. DNA isolated from $\mathrm{SJL} / \mathrm{J}$ liver, SC-derived T cell lines and sublines, a PB-derived T cell line, and an $\mathrm{LN}$-derived $\mathrm{T}$ cell line was cut to completion with Hind III and hybridized to ${ }^{32} \mathrm{P}$-labeled Jbeta 1 probe. Lane $a, \mathrm{SJL} / \mathrm{J}$ liver; lane $b$, JHL; lane $c$, SC-6; lane $d$, SC-5; lane $e$, PB-5; lane $f$, SC-5.0.9.

that none of the lines studied, except SC-2.17.17.11, was rigorously cloned.

Comparison of the restriction fragments obtained with Hind III digestion and a Jbeta 1 probe demonstrates that SC-2 (and its sublines), SC-3, SC-4 (and its sublines) (Fig. 1, lanes $a-g$; Fig. 2, lane $d$ ), and SC-5, SC-5.0.9, and PB-5 (Fig. 3, lanes $d-f$ ) all share a rearranged band at $\sim 14.5 \mathrm{~kb}$. (The germ-line band, seen with Hind III digestion of SJL/J liver DNA and the Jbeta 1 probe, is seen in Fig. 1, lane $i$; Fig. 2, lane $b$; and Fig. 3, lane $a$.) The $\mathrm{LN}$-derived line JHL also demonstrates this rearranged band (this band appears only very faintly in Fig. 3, lane $b$ ). As seen in Fig. 1, lane $h$, line SC-9-PPD demonstrates no bands with the Jbeta 1 probe which suggests that both Jbeta 1 gene segment homologues have been deleted. SC-3, SC-4 and its sublines (Fig. 1, lanes $a$ and $e-g$ ), and SC-5.0.9 (Fig. 3, lane $f$ ) demonstrate deletion of the other Jbeta 1 allele. SC-2 and its sublines, including the clone SC-2.17.17.11, reveal a second beta 1 band of $\sim 13 \mathrm{~kb}$ (Fig. 1, lanes $b-d$ and Fig. 2, lane $d$ ). In addition, SC-5 also demonstrates a second beta 1 rearranged band at $\sim 8.8 \mathrm{~kb}$ (Fig. 3, lane $d$ ). This band $(8.8 \mathrm{~kb}$ ) is also seen in PB-5 in addition to the $14.5-\mathrm{kb}$ band and a beta 1 germ-line band (Fig. 3, lane $e$ ). In contrast, SC-6 does not reveal the $14.5-\mathrm{kb}$ band shared by all the other lines studied (Fig. 3, lane c).

As seen in Fig. 4, lanes $a$ and $e-g$, use of the Jbeta 2 probe and Hind III digestion reveals a germ-line band for SC-3 and 


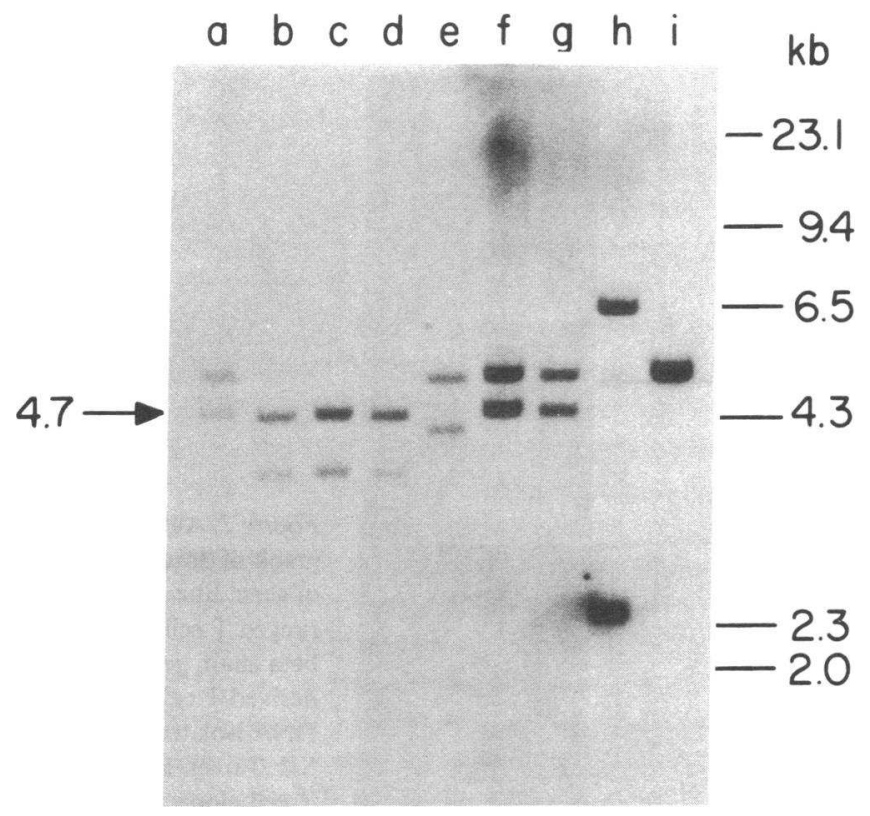

Figure 4. Autoradiograph of Southern blot of germ line and rearranged $\mathrm{T}$ cell receptor beta chain genes. DNA isolated from $\mathrm{SJL} / \mathrm{J}$ liver and SC-derived $\mathrm{T}$ cell lines and sublines from $\mathrm{SJL} / \mathrm{J}$ mice with EAE was cut to completion with Hind III and hybridized to ${ }^{32} \mathrm{P}-\mathrm{la}-$ beled Jbeta 2 probe. A band at $4.7 \mathrm{~kb}$ appears to be shared by SC-2 and its sublines and SC-4 and its sublines. Lane $a$, SC-4; lane $b$, SC-2; lane $c$, SC-2.10; lane $d$, SC-2.17; lane $e$, SC-3; lane $f$, SC-4.1; lane $g$, SC-4.7; lane $h$, SC-9-PPD; lane $i$, SJL/J liver.

SC-4 and its sublines. (The germ-line band, seen with Hind III digestion of SJL/J liver DNA and the Jbeta 2 probe, is seen in Fig. 4, lane $i$; Fig. 5, lane $b$; and Fig. 6, lane $a$.) In addition, SC-2 and SC-4 and their sublines appear to share a rearranged band at $4.7 \mathrm{~kb}$ (Fig. 4 , lanes $a-d$, $f$, and $g$,), whereas SC-3 has a rearranged band at a slightly faster mobility (Fig. 4, lane $e$ ). SC-2 and its sublines, including the clone SC-2.17.17.11, have a second Jbeta 2 Hind III rearrangement at $3.9 \mathrm{~kb}$ (Fig. 4, lanes $b-d$ and Fig. 5, lane $d$ ). PB-5 demonstrates several beta 2 rearrangements (Fig. 6, lane $e$ ), one of which is seen in SC-5 (Fig. 6, lane $d$ ), and another of which is seen in SC-5.0.9 (Fig. 6, lane $f$ ). In addition, SC-5, PB-5, and SC-5.0.9 all demonstrate a Jbeta 2 Hind III germ-line band (Fig. 6, lanes $d-f$ ). It is noteworthy that, in addition, PB-5 has one rearranged band of $4.9 \mathrm{~kb}$ (Fig. 6, lane $e$ ) that is seen in neither SC-5 nor SC-5.0.9 (Fig. 6, lanes $d$ and $f$ ). SC-6 demonstrates a germ-line band and a rearranged Jbeta 2 Hind III band (Fig. 6, lane $c$ ).

One possible interpretation of these restriction bands is that for SC-3, SC-4, its sublines, and SC-5.0.9, one chromosome (of the predominant clones within these lines) has a beta 1 rearrangement (the shared $14.5-\mathrm{kb}$ fragment), while the Jbeta 2 gene segment of that chromosome is in the germ-line configuration. In this interpretation, the other chromosome has its Jbeta 1 segment deleted with a rearrangement into the Jbeta 2 region. SC-3, SC-4, their sublines, and SC-5.0.9 apparently demonstrate different rearrangements of this second chromosome. SC- 2 uses the same $14.5-\mathrm{kb}$ beta 1 rearrangement as the other lines but has a rearranged beta 2 band on the same chromosome. The other chromosome appears to have both Jbeta 1 and Jbeta 2 gene segment rearrangements. The simultaneous appearance of both beta 1 and beta 2 rearrange-

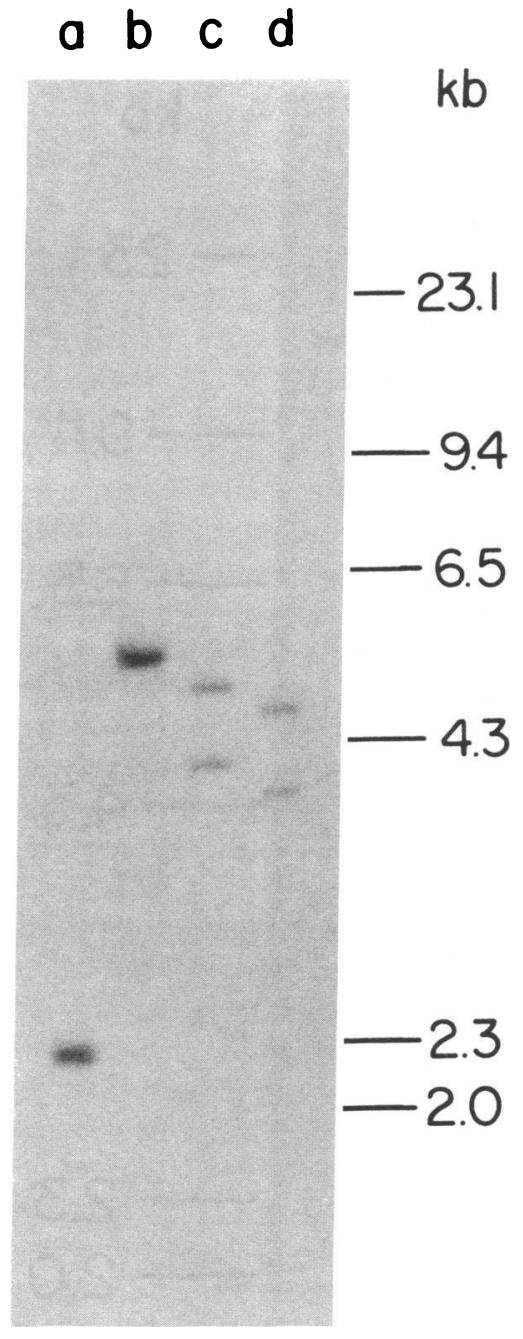

Figure 5. Autoradiograph of Southern blot of germ line and the rearranged $T$ cell receptor beta chain genes of an SC-derived T cell clone. DNA isolated from $\mathrm{SJL} / \mathrm{J}$ liver and SC-2.17.17.11, a T cell clone derived from an SJL/J mouse with EAE, was cut to completion with Eco RI or Hind III and hybridized to ${ }^{32} \mathrm{P}$ labeled Jbeta 2 probe. Lane $a$, Eco R 1 digest of $\mathrm{SJL} / \mathrm{J}$ liver; lane $b$, Hind III digest of SJL/J liver; lane $c$, Eco RI digest of SC-2.17.17.11; lane $d$, Hind III digest of SC-2.17.17.11.

ments on the same chromosome may be explained by nonproductive Dbeta 2-Jbeta 2 rearrangements (17). SC-5 also demonstrates two beta 1 rearrangements but appears to have one beta 2 rearrangement and a germ-line band. Given this pattern, a putative chromosomal configuration for SC-5 may involve the $14.5-\mathrm{kb}$ beta 1 band together with the germ-line beta 2 , or the $14.5-\mathrm{kb}$ beta 1 band with a beta 2 nonproductive rearranged band. SC- 6 , on the other hand, has a beta 1 rearrangement (not to $14.5 \mathrm{~kb}$ ) with a germ-line configuration of the beta 2 on one chromosome, and a deleted beta 1 with a rearranged beta 2 on the other chromosome. For all of the lines these chromosomal configurations can only be conjectural at this point.

SC-2, SC-4, and their sublines appear to share a rearranged beta 2 band of $4.7 \mathrm{~kb}$. This band, which travels slightly faster than the germ-line band, may represent a Dbeta 2-Jbeta 2 nonproductive rearrangement. No other shared rearranged band was seen among all of the SC-derived lines, including SC-9-PPD. Eco R1, which also allows detection of all rearrangements with the Jbeta probes, gave similar results on Southern blot analysis as those shown for Hind III (Fig. 2, lane $c$; and Fig. 5, lane $c$, for SC-2.17.17.11; rest of data not shown).

In addition, DNA was obtained from several SJL/J LN-derived $T$ cell lines with antigen reactivities other than MBP. As seen in Fig. 7, two OVA-reactive lines, OVA 0.15 and OVA 


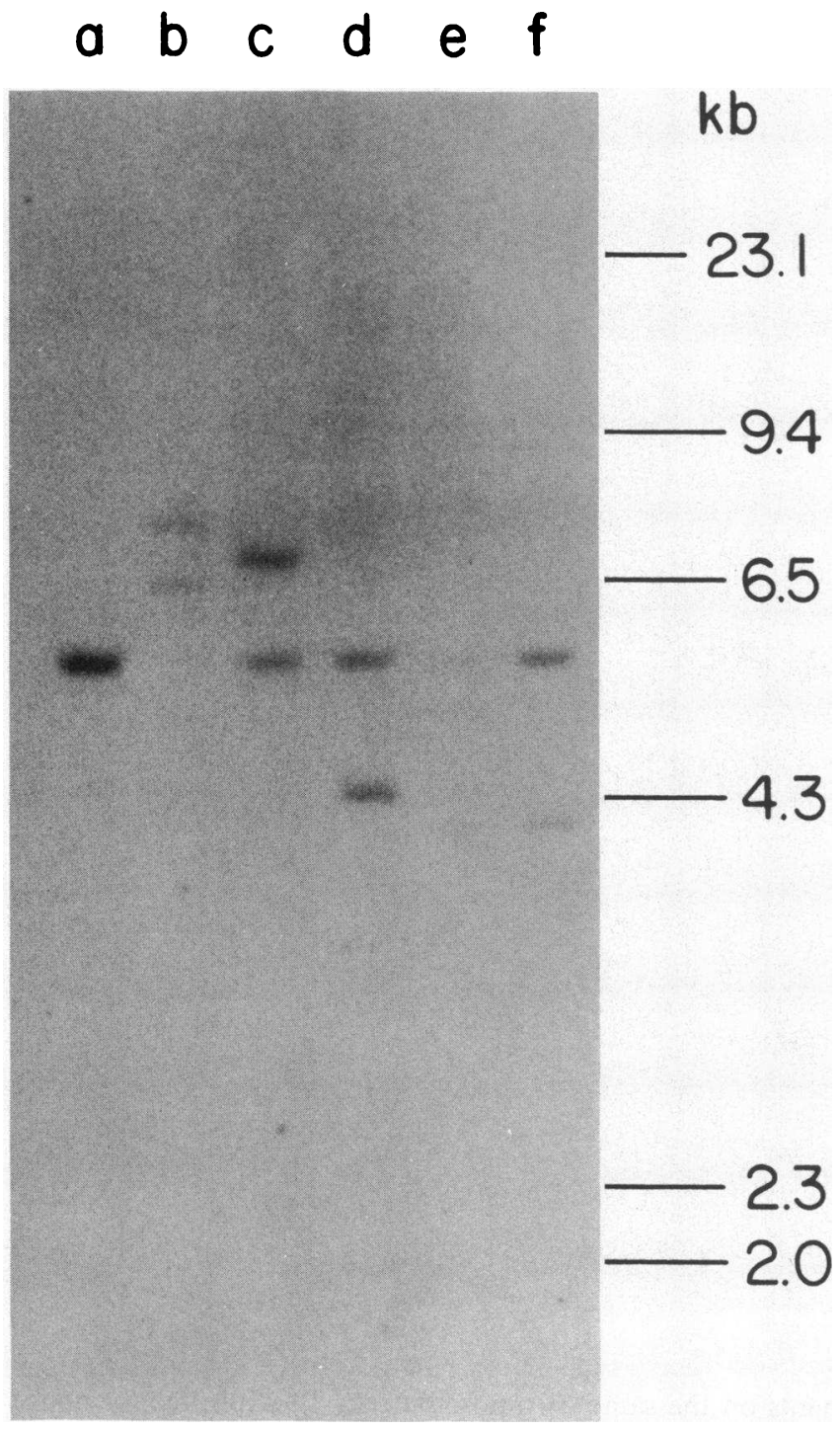

Figure 6. Autoradiograph of Southern blot of germ line and rearranged $T$ cell receptor beta chain genes. DNA isolated from $\mathrm{SJL} / \mathrm{J}$ liver, SC-derived T cell lines and sublines, a PB-derived T cell line, and an LN-derived $\mathrm{T}$ cell line was cut to completion with Hind III and hybridized to ${ }^{32} \mathrm{P}$-labeled Jbeta 2 probe. Lane $a, \mathrm{SJL} / \mathrm{J}$ liver; lane $b$, JHL; lane $c$, SC-6; lane $d$, SC-5; lane $e$, PB-5; lane $f$, SC-5.0.9.

1.24, did not demonstrate the $14.5-\mathrm{kb}$ band when hybridized with the Jbeta 1 probe. DNA from a PPD-reactive, LN-derived line, PPD 1.24, did not hybridize to the Jbeta 1 probe, which suggests rearrangement to Jbeta 2 on both chromosomes with deletion of both Jbeta 1 gene segments (data not shown).

In light of the same general antigen reactivity of all of the SC-lines and the shared $14.5-\mathrm{kb}$ beta 1 band of four of five of these lines, it seems likely that, with two possible exceptions, the $T$ cell receptor beta chain of the predominant clone in each population is encoded by this $14.5-\mathrm{kb}$ beta 1 rearrangement. The two exceptions are SC-6, which is reactive to murine MBP, though it does not demonstrate the shared $14.5-\mathrm{kb}$ beta 1 rearrangement, and PB-5, which has lost its murine MBP reactivity, yet still demonstrates the shared $14.5-\mathrm{kb}$ beta 1 rearrangement. The loss of the murine MBP response of PB-5 is most likely explained by a quantitative decrease in the popula-

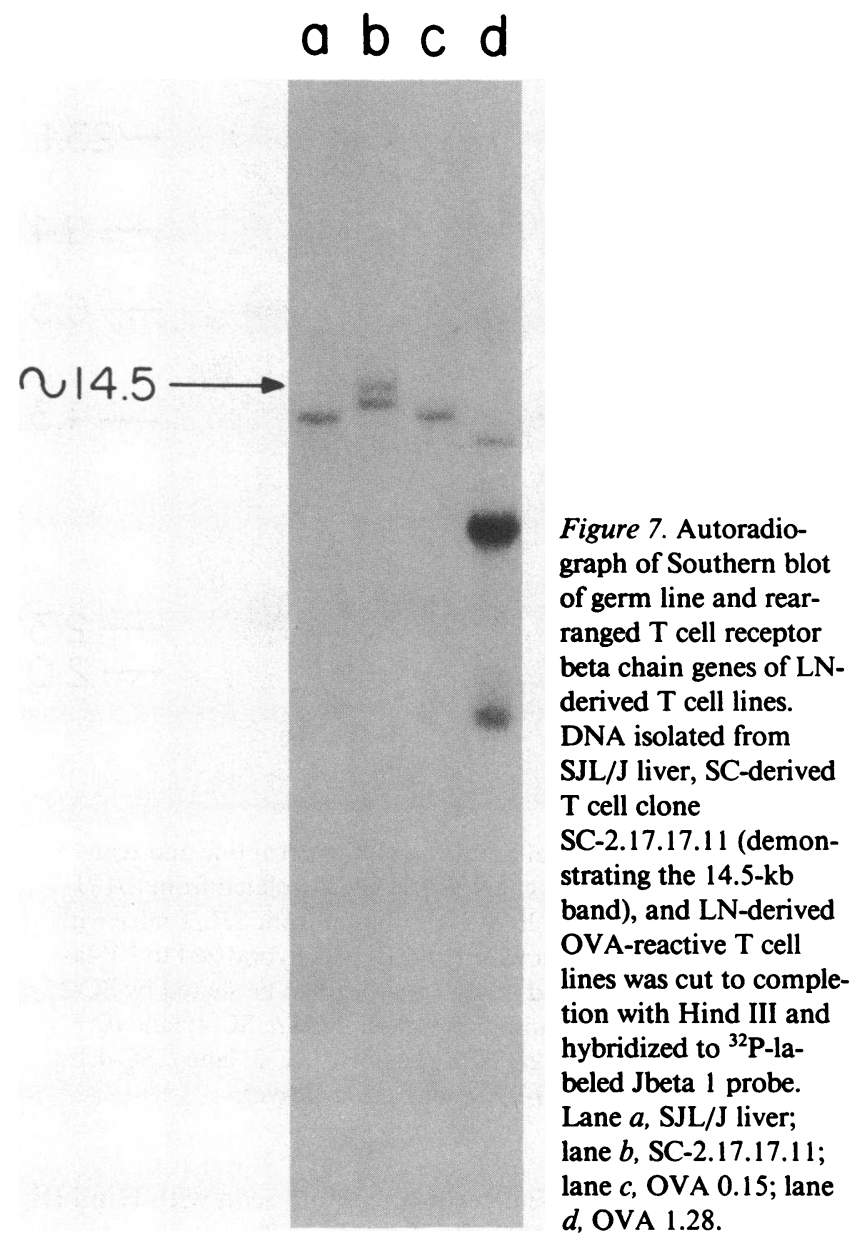

tion that is responsive to murine MBP, which is nevertheless still identifiable on the Southern blots. SC-6 is likely to be responsive to a tertiary conformational epitope (or an overlap determinant) on the MBP molecule that is different from that recognized by the other four SC-derived lines. The precise structure-function relationship of these receptors, however, awaits complete sequencing of the DNA that encodes for the alpha and beta chains of the receptors. Nevertheless, our results indicate that a common pattern of beta chain rearrangements can be seen on Southern blot analysis of site-of-pathology, self-reactive $T$ cells.

\section{Discussion}

A significant body of knowledge has accumulated over the past few years elucidating the structure and molecular biology of the $T$ cell antigen receptor. Despite these advances, the relationship between the structure and the function of the $T$ cell receptor is only beginning to be understood. In this report we have initiated studies testing the feasibility of identifying disease-related $T$ cells in autoimmune diseases through the analysis of the antigen receptors used by $T$ cells derived from the sites of autoimmune inflammation. Our initial characterization has involved Southern blot analysis of the $\mathrm{T}$ cell antigenreceptor beta chain gene rearrangements of $\mathrm{T}$ cell lines derived from the SCs of five mice with EAE. We have identified a common beta 1 chain gene rearrangement used by the SC-derived $\mathrm{T}$ cell lines from four of five mice with EAE. 
It is important to note that the $14.5-\mathrm{kb}$ beta 1 rearrangement shared among SC-2, $-3,-4$, and -5 is not seen in either SC-9-PPD or SC-6. The latter two lines were also derived from the SCs of SJL/J mice with EAE, thus demonstrating that the shared rearrangements are not related to the methods by which $\mathrm{T}$ cell lines and clones were generated from the SCs. Furthermore, the Southern blot of SC-6 as well as the phenotypic heterogeneity of proliferative responses (e.g., the JHL fragment responses and the lack of a murine-MBP response among most of our PB-derived lines [9]), demonstrate that the shared rearrangements among SC-2, $-3,-4$, and -5 are not simply a result of in vitro selection by our methods of propagation. It is also noteworthy that PB-5 demonstrated rearrangements (specifically, beta 2 rearrangements) that were not seen with SC-5, though both were derived from the same mouse, at the same time, and were propagated similarly. This finding of $T$ cell receptor beta chain rearrangements within the PB-5 line that were not demonstrated in the blots of SC-5 suggest that the cells derived from the cords have at least a quantitative composition different from those in the PB despite the use of similar in vitro propagation protocols. That this difference may in fact be quantitative rather than qualitative is suggested by the finding that SC-5.0.9, a 1-cell/well subculture of SC-5, demonstrates a beta 2 rearrangement that is different from the one seen in SC-5, but similar to one of those seen in PB-5. Thus, while there are populations present in SC-5 that may not have been seen on these Southern blots and may be similar to those present in PB-5, the clonal compositions of the SC and $P B$ populations derived from the same mouse with EAE differ at least quantitatively. Furthermore, it should again be noted that murine MBP responses were not usually found among our PB-derived lines and that PB-5 was studied because it was the only PB line that demonstrated even a small murine MBP response (9).

The finding of a common beta chain gene rearrangement used by long-term, IL-2-dependent, MBP-reactive lines derived from the SCs of four of five different mice with EAE suggests that this approach may have applicability as an initial approach in the study of certain human autoimmune diseases. Thus, theoretically, it would have been possible to identify and isolate the four SC-derived lines that possess a common beta chain rearrangement and to distinguish these lines from the SC-derived PPD-specific line, even in the absence of knowing the antigen specificities of the lines. However, it should be noted that a number of significant differences exist between applying this approach to the study of human autoimmune diseases and the study of EAE described in this paper. Such differences include $(a)$ the central nervous system-derived lines in this study were generated during many weeks of in vitro propagation in the presence of the known autoantigen, MBP, and therefore in vitro selection for MBP-responsive populations (though not necessarily for murine MBP-responsive populations) has occurred; in the human disease the relevant antigens are unknown; however, we have previously demonstrated that using anti-T3 antibodies in lieu of relevant antigens does maintain the antigen reactivities of long-term propagated lines $(3,4) ;(b)$ SJL mice have a $50 \%$ decrease in the number of beta variable region gene segments (18) and thus the likelihood of finding a common rearrangement may be increased in this experimental model; however, the heterogeneity of $\mathrm{T}$ cell receptors used in the SJL/J murine MBP response does not appear to be extremely limited. Phenotypic heterogeneity of this response is suggested both by the fragment response of line JHL and by the variation in MBP fragment responses seen among $\mathrm{LN}$-derived $\mathrm{T}$ cell clones reported by others (16). In addition, genotypic heterogeneity of the murine MBP response is suggested by our finding of a nonshared rearrangement used by line SC-6. Furthermore, we have shown that $\mathrm{SJL} / \mathrm{J} \mathrm{LN}$-derived $\mathrm{T}$ cell lines reactive to antigens other than MBP do not demonstrate the 14.5-kb rearrangement for their T cell receptor beta chain genes; $(c)$ all of the T cell lines studied were derived from the inflammatory site at approximately the same time point in the inflammatory process (this may be difficult to accomplish in the human studies); and $(d)$ the present experimental system involves mice that are syngeneic and thus the $T$ cell lines and clones recognize MBP in the context of the same MHC determinants. However, in the human studies this may also be the case in that diseases such as MS and RA are known to be associated with increased frequencies of certain DR determinants $(19,20)$. While our model involves the optimal conditions under which this approach should work, the present results nevertheless suggest that a similar analysis of $T$ cell receptor rearrangements could be of significant utility in allowing for the initial identification of those site-of-inflammation $\mathrm{T}$ cells most likely to be relevant to the initiation and/or propagation of human diseases such as MS or RA.

Similarities in beta chain rearrangements using Southern blot analysis do not define similarities of the entire $T$ cell receptor. Hedrick and Matis and their colleagues have evaluated the $T$ cell receptors used by $T$ cell clones specific for related but clearly different antigens $(5,6)$. In their studies they found that their clones used a limited number of variable region genes for both the alpha and beta chains. They concluded that specific antigen/MHC-restricted reactivity is encoded by a combination of the alpha and beta chains and could not be assigned to a specific region or chain of the $T$ cell receptor. However, they did find that variation of the beta chain correlated with changes in fine antigen specificity and that alloreactivity was associated with the use of a particular alpha chain $\mathbf{J}$ region gene. It is clear that our results can only constitute a first approximation of the $\mathrm{T}$ cell receptors being used by SC-derived $\mathrm{T}$ cells in EAE. The next phase of our studies, which involves the more precise definition of the alpha and beta chains of these lines and clones by cDNA sequencing, is presently ongoing. However, the purpose of the present study was to determine the feasibility of using beta chain Southern blot analysis as the initial screen for site-of-inflammation $T$ cell oligoclonality. The present results indeed suggest that $T$ cell receptor-beta chain analysis of site-of-inflammation-derived $T$ cell clones may be useful as the initial approach for isolating (for further in-depth study) the pathogenetically relevant $T$ cells in certain human autoimmune diseases. We are presently using this approach to characterize the $\mathrm{T}$ cell receptor-beta chain gene rearrangements used by synovial-derived $T$ cell clones obtained from patients with RA, and the receptor-beta chain gene rearrangements used by cerebrospinal fluid-derived $\mathrm{T}$ cell clones obtained from patients with MS.

\section{Acknowledgments}

We are grateful to Drs. David Rowe, Alex Lichtler, Mark Ballow, and Peter Setlow for their helpful discussions, Felicia LaMontagne for her technical assistance, and Susan Roman for her secretarial assistance. 
This work was supported by the National Multiple Sclerosis Society grants RG-1386-A-1 (R. B. Clark) and RG-1543-B17 (C.-H. J. Chou) and a National Institutes of Health (NIH) Multipurpose Arthritis Center grant (AM-20621). Dr. Padula is a recipient of an Arthritis Foundation Postdoctoral Fellowship, a Lupus Research Institute Scholar Award, and a Culpepper Foundation Scholar Award. Dr. Clark is a recipient of support from the Chicago Community Trust/ Searle Scholars Program and is a recipient of an NIH Research Career Development Award (AM-01140). D. Sgroi is a recipient of a University of Connecticut Medical Student Research Fellowship.

\section{References}

1. Clark, R. B., S. P. Muirhead, and M. K. Pollard. 1984. Generation of long-term T-cell lines from synovial fluid. Clin. Immunol. Immunopathol. 33:287-292.

2. Clark, R. B., P. Dore-Duffy, J. O. Donaldson, M. K. Pollard, and S. P. Muirhead. 1984. Generation of phenotypic helper/inducer and suppressor/cytotoxic $\mathrm{T}$ cell lines from cerebrospinal fluid in multiple sclerosis. Cell. Immunol. 84:409-414.

3. Padula, S. J., M. K. Pollard, E. G. Lingenheld, and R. B. Clark. 1985. Maintenance of antigen specificity by human interleukin-2-dependent $T$ cell lines: use of antigen-presenting cells and OKT3 antibody in the absence of antigen. J. Clin. Invest. 75:788-797.

4. Clark, R. B., E. G. Lingenheld, J. O. Donaldson, and M. K. Pollard. 1985. Compartmentalized immune responses: antigen-specificity of cerebrospinal fluid T-cell lines maintained in the absence of antigen. Clin. Immunol. Immunopathol. 36:176-186.

5. Fink, P. J., L. A. Matis, D. L. McElligott, M. A. Bookman, and S. M. Hedrick. 1986. Correlations between T-cell specificity and the structure of the antigen receptor. Nature (Lond.). 321:219-226.

6. Sorger, S. B., S. M. Hedrick, P. J. Fink, M. A. Bookman, and L. A. Matis. 1987. Generation of diversity in T cell receptor repertoire specific for pigeon cytochrome. J. Exp. Med. 165:279-301.

7. Hochqeschwender, U., H.-G. Simon, H. U. Weltzieu, F. Bartels, A. Becker, and J. T. Epplen. 1987. Dominance of one T-cell receptor in the H-2 $\mathrm{K}^{\mathrm{b}} / \mathrm{TNP}$ response. Nature (Lond.). 326:307-309.

8. Zamvil, S., P. Nelson, J. Trotter, D. Mitchell, R. Knobler, R. Fritz, and L. Steinman. 1985. T cell clones specific for myelin basic protein induce chronic relapsing paralysis and demyelination. Nature (Lond.). 317:355-358.
9. Sgroi, D., R. N. Cohen, E. G. Lingenheld, M. K. Strong, T. Binder, I. Goldschneider, D. Greiner, M. Grunnet, and R. B. Clark. 1986. T cell lines derived from the spinal cords of mice with experimental allergic encephalomyelitis are self reactive. J. Immunol. 137:1850-1854.

10. Knobler, R. L., D. S. Linthicum, and M. Cohn. 1985. Host genetic regulation of acute MHV-4 viral encephalomyelitis in (Balb/c $\mathrm{Ke} \times \mathrm{SJL} / \mathrm{J})$ recombinant-inbred mice. J. Neuroimmunol. 8:15-28.

11. Norton, W. T., and S. E. Paduslo. 1973. Myelination in rat brain: method of myelin isolation. J. Neurochem. 21:749-757.

12. Chou, C.-H. J., J. C. R. Shapiro, and R. B. Fritz. 1984. Further delineation of encephalitogenic determinant for PL/J and (SJL $\times \mathrm{PL}_{1} \mathrm{~F}_{1}$ mice. In EAE: A Good Model for MS. E. C. Alvrod, M. W. Kies, and A. J. Suckling, editors. Alan R. Liss, Inc., New York. 229-234.

13. Gusella, J., A. Varsanyi-Breiner, F. Kao, C. Jones, T. T. Puck, C. Keys, S. Orkin, and D. Housman. 1979. Precise localization of human B-globin gene complex on chromosome II. Proc. Natl. Acad. Sci. USA. 76:5239-5243.

14. Southern, E. M. 1975. Detection of specific sequences among DNA fragments separated by gel electrophoresis. J. Mol. Biol. 98:503-517.

15. Feinberg, A. P., and B. Vogelstein. 1983. A technique for radiolabeling DNA restriction endonuclease fragments to high specific activity. Anal. Biochem. 132:6-13.

16. Trotter, J., S. Sriram, L. Rassenti, C. H. J. Chou, R. B. Fritz, and $L$. Steinman. 1985. Characterization of $T$ cell lines and clones from $\mathrm{SJL} / \mathrm{J}$ and $(\mathrm{Balb} / \mathrm{c} \times \mathrm{SJL} / \mathrm{J}) \mathrm{F}_{1}$ mice specific for myelin basic protein. J. Immunol. 134:2322-2327.

17. Kronenberg, M., J. Goverman, R. Haars, M. Malissen, E. Kraig, L. Phillips, T. Delovitch, N. Suciu-Foca, and L. Hood. 1985. Rearrangement and transcription of the beta-chain genes of the T-cell antigen receptor in different types of murine lymphocytes. Nature (Lond.). 313:647-653.

18. Behlke, M. A., H. S. Chou, K. Huppi, and D. Y. Loh. 1986. Murine T-cell receptor mutants with deletions of beta-chain variable region genes. Proc. Natl. Acad. Sci. USA. 83:767-771.

19. Batchelor, J. R., A. Compston, and W. I. McDonald. 1978. The significance of the association between HLA and multiple sclerosis. $\mathrm{Br}$. Med. Bull. 34:279-284.

20. Stastny, P. 1978. Association of the B-cell alloantigen DRw4 with rheumatoid arthritis. N. Engl. J. Med. 298:869-871. 